\title{
Retraction Note to: Environmental planning and economic efficiency of green cities based on improved neural network and satellite remote sensing
}

\section{Yeung Lap-fu ${ }^{1}$}

Published online: 6 December 2021

(c) Saudi Society for Geosciences 2021

Retraction Note to: Arabian Journal of Geosciences (2021) 14: 1399

https://doi.org/10.1007/s12517-021-07657-4

The Editor-in-Chief and the Publisher have retracted this article because the content of this article is nonsensical. The peer review process was not carried out in accordance with the Publisher's peer review policy. The author has not responded to correspondence regarding this retraction.

The original article can be found online at https://doi.org/10.1007/ s12517-021-07657-4.

Yeung Lap-fu

chineselawhk@sina.com

1 Civil, Commercial and Economic Law School, China

University of Political Science and Law, Beijing 100088,

China 